\title{
ACTOS INTERMEDIOS Y RECURSO DE PROTECCIÓN AMBIENTAL
}

[Intermediate Acts and Remedy for Environmental Protection]

\author{
Juan Pablo Leppe GuZmán*
}

\begin{abstract}
Resumen
En el artículo se analiza la utilización del distingo entre actos administrativos intermedios y finales como criterio para resolver recursos de protección ambientales fundados en la supuesta ilegalidad de actos del procedimiento de evaluación ambiental. Se analiza la aplicación del referido criterio y la argumentación que la sustenta a la luz del régimen jurídico de la acción de protección y de la interpretación que otros órganos del Estado hacen de los actos trámite.
\end{abstract}

\section{Palabras Clave}

Actos administrativos intermedios Actos administrativos finales - Recurso de Protección.

\begin{abstract}
This article analyzes the use of the distinction between intermediate and final administrative acts as a criterion to solve remedies for environmental protection based on an alleged illegality in the acts of the environmental assessment procedures. We study how said criterion is applied and its grounds in the light of the regulatory system for the remedy of protection and how other state agencies construe formality acts.
\end{abstract}

\section{KEYWORDS}

Intermediate administrative Acts Final administrative acts - Remedy for Protection.

RECIBIDO el 9 de septiembre y ACEPTADo el 9 de diciembre de 2013

* Licenciado en Ciencias Jurídicas, Máster Avanzado en Ciencias Jurídicas por la Universidad Pompeu Fabra y diplomado en Derecho Ambiental por la Pontificia Universidad Católica de Valparaíso. Correo electrónico: jpleppe@yahoo.com 


\section{INTRODUCCIÓN}

Una clasificación que ha cobrado especial fuerza en el Derecho administrativo es la que distingue entre actos administrativos de dos categorías: intermedios, preparatorios, trámite o de mero trámite; y decisorios, de término, resolutorios o terminales ${ }^{1}$. No obstante lo cual, son contados los autores nacionales que han abordado la clasificación con alguna profundidad.

Antes de la promulgación de la Ley $N^{\circ} 19.880$, que establece Bases de los procedimientos administrativos que rigen los actos de los órganos de la Administración del Estado, Silva Cimma definía los "actos de trámite" como "las providencias administrativas que la Administración debe disponer para mejor resolver un asunto de su competencia, materia respecto de la cual en nuestro país debe tenerse presente la norma del artículo 8 , inciso $2^{\circ}$ de la Ley $\mathrm{N}^{\circ} 18.575$ de 1986 , ya citada, en cuanto ordena que los procedimientos administrativos deben ser "ágiles y expeditos"2.

Una vez en vigor la citada ley de procedimientos y a la luz de sus normas, Rojas propuso la definición que sigue: "los actos trámite son presupuesto de la decisión de fondo. Son actos previos a la resolución que ordenan el procedimiento, como son, por ejemplo: los actos de incoación, de instrucción, comunicaciones, notificaciones. No son impugnables en sede administrativa, salvo que determinen la imposibilidad de continuar el procedimiento o produzcan indefensión"

El legislador por su parte se ha valido de la clasificación referida, inter alia, para articular una definición de procedimiento administrativo ${ }^{4}$, para regular la impugnabilidad de los actos emanados de la Administración del

${ }^{1}$ Si bien Silva Cimma, Enrique, Derecho administrativo chileno y comparado. Actos, contratos y bienes (Santiago, Editorial Jurídica de Chile, 1995), V, p. 82. ss., aborda por separado los "actos preparatorios" de los "de trámite", creemos que ambos conceptos comparten un significado común y que la diferencia de nombre obedece solo a los criterios con que clasificó los actos administrativos para efectos pedagógicos, correspondiendo el concepto "acto preparatorio" a una clasificación basada en el rol del acto en la decisión administrativa, y el de "acto de "trámite" a una realizada en función del contenido mismo del acto.

${ }^{2}$ Silva Cimma, E., cit. (n. 1), p. 85.

${ }^{3}$ Rojas, Jaime, Notas sobre el procedimiento administrativo establecido en la Ley $N^{o}$ 19.880, en Revista de Derecho del Consejo de Defensa del Estado, 11 (2004), p. 1.

${ }^{4}$ En el artículo 18 inciso $1^{\circ}$ de la Ley $N^{\circ} 19.880$ se define el procedimiento administrativo como: “[...] una sucesión de actos trámite vinculados entre sí, emanados de la Administración y, en su caso, de particulares interesados, que tiene por finalidad producir un acto administrativo terminal”. 
Estado en el marco del procedimiento ordinario ${ }^{5}$ y al señalar las exigencias que debe satisfacer un acto de término ${ }^{6}$.

Los jueces de los tribunales superiores de justicia a su vez, han venido distinguiendo ${ }^{7}$ entre actos de trámite y decisorios ${ }^{8}$ al resolver recursos de protección incoados en relación con actos de la Administración supuestamente ilegales. Actos que emanan de organismos con competencia ambiental y que se dictan en el marco del procedimiento administrativo de evaluación ambiental'.

\section{JURISPRUDENCIA}

DEL PERÍODO ENTRE JUNIO DE 2011 Y JUNIO 2013

En junio de 2011 la Corte de Apelaciones de Coyhaique rechazó un recurso de protección intentado contra la Comisión de Evaluación Ambiental de la Región de Aysén, fundado en la supuesta ilegalidad de la citación a la sesión de calificación ambiental de un proyecto hidroeléctrico (recurso rol No 24-2011). Dijo: "Que, de lo anterior, aparece claro que el acto impugnado por la recurrente, cual es la convocatoria o citación efectuada por la Comisión Ambiental a una sesión de calificación ambiental del Proyecto, fjada para el dia 9 de mayo de 2011, no es más que un trámite procesal ordenatorio en un procedimiento administrativo fijado por la ley, el cual no puede generar efectos respecto de terceros, careciendo este simple mandato, esto es, el de citar a una sesión o reunión, de la aptitud, idoneidad o eficacia para agraviar algún derecho constitucional, atendida la naturaleza jurídica de dich a citación, que sólo dispone el cumplimiento de una norma reglamentaria que tiene su sustento en la Ley 19.300, sobre Bases Generales del Medio Ambiente"10.

En octubre de 2011, resolviendo la apelación de la sentencia recaída en un recurso de protección relativo a un proyecto de transmisión eléctrica (recurso rol No 7342-2011), la Sala Constitucional de la Corte Suprema

${ }^{5}$ En el artículo 15 inciso $2^{\circ}$ de la precitada ley, se alude a los “actos de mero trámite".

${ }^{6}$ En el artículo 41 de ella se emplea la expresión "resolución final”.

${ }^{7}$ Ya en el año 2007 Rafael VARGAS aludía al fenómeno en su obra Instituciones de Derecho ambiental. El recurso de protección ambiental (Santiago, Metropolitana, 2007), pp. 456 ss.

${ }^{8}$ No obstante hablen de "actos intermedios" y "actos terminales".

${ }^{9}$ Procedimiento especial, complejo y reglado; regulado en la Ley No 19.300 y el Decreto supremo No 30/1997, del Ministerio Secretaría General de la Presidencia, que promulgó el Reglamento del sistema de evaluación de impacto ambiental, cuyo texto refundido, coordinado y sistematizado fue fijado con el Decreto $\mathrm{N}^{\circ} 95 / 2001$, del mismo Ministerio. Mora.

${ }^{10}$ Considerando $9^{\circ}$ de la sentencia redactada por el ministro señor Sergio Fernando 
dictaminó: "Que aparece claro entonces que los actos cuestionados constituyen actos intermedios o de trámite de un procedimiento complejo (dos Adendas y un Informe Consolidado de Solicitud de Aclaraciones, Rectificaciones o Ampliaciones), que han sido dispuestos conforme a un orden consecutivo legal que tanto los titulares como las autoridades administrativas deben seguir en los análisis de los proyectos a actividades que deben ser sometidos al Sistema de Evaluación de Impacto Ambiental. En la especie, las actuaciones contra las que se recurre han sido desarrolladas en el marco de un procedimiento de evaluación ambiental respecto de la modificación del trazado de un tendido eléctrico que, a la fecha de interposición de este recurso de protección, aún no concluia./ Que de esta manera los actos censurados, en cuanto fueron desplegados en cumplimiento de la legislación que rige esta materia y cuy a finalidad apunta a dictar el acto administrativo terminal (resolución de calificación ambiental, según se desprende de la lectura del considerando primero) que es resolver si un proyecto o actividad se ajusta a la normativa ambiental, carecen de la aptitud necesaria para amenazar cualquier garantía constitucional, pues como actos intermedios no pueden generar efecto alguno en tal sentido./ Que, acorde a lo antes expuesto, el recurso de protección no puede prosperar porque no concurre el presupuesto favorable a esta acción de que el acto denunciado tenga la aptitud deprivar, perturbar o amenazar el legitimo ejercicio de los derechos y garantias constitucionales cautelados mediante este recurso" ${ }^{11}$.

En octubre de 2012, la Corte de Apelaciones de Copiapó rechazó un recurso de protección deducido por una comunidad agrícola indígena en el marco de la evaluación ambiental de un proyecto de inversión minero (recurso rol No 250-2012); y argumentó: “Que por otro lado, tampoco puede perderse de vista que las actuaciones impugnadas constituyen meros actos trámites -que no son los únicos-, inmersos en el procedimiento de Evaluación de Calificación Ambiental, del cual el Informe Consolidado de Solicitud de Aclaraciones, Rectificaciones y/o Ampliaciones 5 no reviste más que la calidad de un acto administrativo preparatorio sin aptitud para causar agravio por si mismo y no corresponde a aquellos actos terminales, que por lo mismo carece de idoneidad para afectar garantía constitucional alguna, lo que igualmente impide acoger el recurso de autos" 12 .

Por último, en marzo de 2013 la Tercera Sala de la Corte Suprema falló en relación a un proyecto de estacionamientos subterráneos (recurso rol $\mathrm{N}^{\circ}$ 8-2013): “Que como se expone en el fundamento tercero, la Resolución en que se contiene el examen de admisibilidad de 29 de agosto de 2012 no resuelve sobre

\footnotetext{
${ }^{11}$ Considerandos $2^{\circ}, 3^{\circ}$ y $4^{\circ}$ de la sentencia redactada por el abogado integrante $\mathrm{Sr}$. Jorge Medina.

${ }^{12}$ Considerando $6^{\circ}$ de la sentencia redactada por el ministro señor Pablo Bernardo
} Krumm. 
la Declaración de Impacto Ambiental, sino que da curso progresivo a la tramitación del proceso de evaluación ambiental, por lo que no tiene la aptitud para amenazar la garantía constitucional consagrada en el $N^{\circ} 8$ del artículo 19 de la Constitución Politica de la República, toda vez que como acto intermedio no puede generar efecto alguno en tal sentido./ Que, acorde a lo expuesto, el recurso de protección no puede prosperar, porque no concurre el presupuesto favorable a esta acción en cuanto a que el acto denunciado y el Oficio emitido tengan la aptitud deprivar,perturbar o amenazar el legitimo ejercicio del derecho a vivir en un medio ambiente libre de contaminación" 13 .

\section{ANÁLISIS PRELIMINAR}

Con las sentencias precitadas los tribunales superiores han sostenido que:

$1^{\circ}$ La naturaleza jurídica de la resolución de calificación ambiental es la de acto administrativo terminal;

$2^{\circ}$ Los actos previos a la resolución de calificación ambiental son actos intermedios o de mero trámite; $\mathrm{y}$

$3^{\circ}$ Estos últimos no tienen aptitud para afectar el ejercicio de derechos constitucionales como los reconocidos en el artículo 19 № 2 y 8 CPol.

a) En principio y atendido el tenor de la ley, la proposición $1^{\text {a }}$ ) no presentaría problemas.

La resolución de calificación ambiental es el acto de término del procedimiento de evaluación ambiental la mayoría de las veces, y con ella se aceptará, aprobará o rechazará las declaraciones de impacto ambiental y los estudios de impacto ambiental ${ }^{14}$. Sin embargo, la proposición en estudio no debiera ser asumida de forma excluyente, entendiendo que no puede haber otros actos de término durante la evaluación y calificación ambiental de un proyecto o actividad, ya que en la práctica existen otros actos que presentan rasgos comunes con los actos finales.

A mayor abundamiento, la judicatura no debiera dejar de fundamentar sus decisiones jurisdiccionales por el hecho de asumir una proposición del modo indicado, pero para abordar la materia, revisemos en primer lugar definiciones de acto administrativo de término.

Antes de la promulgación de la Ley No 19.880, el profesor Caldera definía el acto terminal como "aquel que contiene la decisión administrativa resolutiva; éste es el acto administrativo llamado a producir de manera di-

${ }^{13}$ Considerandos $9^{\circ}$ y $10^{\circ}$ de la sentencia redactada por la ministro señora María Eugenia Sandoval.

${ }^{14}$ Ello de conformidad con lo dispuesto en el artículo 24 de la Ley № 19.300. 
recta los efectos indicados por la Administración, y que están expresamente comprendidos en la competencia del órgano que lo emite"15.

Ya con la ley que establece Bases de los procedimientos administrativos que rigen los actos de los órganos de la Administración del Estado a la vista, podríamos definir el acto de término como "aquel acto administrativo que pone fin al procedimiento decidiendo las cuestiones planteadas por los interesados en forma fundada, con mención de los recursos procedentes y que debe ajustarse a las peticiones formuladas por el interesado, sin agravar su situación inicial si el procedimiento se ha tramitado a solicitud suya”.

Luego, si bien la resolución de calificación ambiental será efectivamente el acto de término de la evaluación ambiental en la generalidad de los casos, cabe recordar que ella bien puede experimentar modificaciones como resultado de la dictación de resoluciones que la sucedan en el tiempo ${ }^{16}$.

Por otra parte, la misma Ley No 19.300 sobre Bases generales del medio ambiente franquea recursos administrativos de reclamación a los titulares que no queden conformes con los términos de una resolución de calificación ambiental ( si con esta no se hace lugar a la declaración de impacto ambiental del proyecto, se rechaza la declaración de impacto ambiental o el estudio de impacto ambiental, o se le establecen condiciones o exigencias), como asimismo a las personas que hayan intervenido en una etapa de participación ciudadana cuyas observaciones no hubieren sido debidamente consideradas en los fundamentos de una resolución de calificación ambiental, para acudir al director ejecutivo del Servicio de Evaluación Ambiental (declaración de impacto ambiental) o al Comité de Ministros $^{17}$ (estudio de impacto ambiental $)^{18}$.

Asimismo, puede solicitarse la invalidación de una resolución de calificación ambiental ${ }^{19}$ e impugnarse por las vías ordinarias administrativas ${ }^{20}$,

${ }^{15}$ Caldera, Hugo, Tratado de Derecho administrativo (Santiago, Ediciones Parlamento, 2001), II, p. 152.

${ }^{16}$ Hipótesis del artículo 25 sexies.

${ }^{17} \mathrm{~A}$ su vez, lo que se resuelva por el Director Ejecutivo o el Comité de Ministros es impugnable ante el Tribunal Ambiental competente, conforme lo dispuesto en el artículo 17, No 5 y N 6 de la Ley No 20.600: que Crea los Tribunales Ambientales.

${ }^{18}$ Artículos 20, 29 inciso final y 30 bis inciso $5^{\circ}$, respectivamente.

${ }^{19}$ El Contralor General de la República estableció en el dictamen No 38.581/2013, que "no se aprecia inconveniente en orden a alegar la invalidación de un acto administrativo en el marco del sistema de evaluación de impacto ambiental siempre que se cumplan los requisitos para ello y que la aplicación supletoria de la señalada ley $N^{\circ} 19.880$ sea conciliable con el procedimiento especial establecido al efecto (aplicando criterio contenido en el dictamen $N^{\circ}$ 12.971/2006)".

${ }^{20} \mathrm{~A}$ su turno, la resolución que resuelve el proceso invalidatorio de un acto administrativo de carácter ambiental, podrá reclamarse ante el Tribunal Ambiental com- 
“estos es, recursos administrativos de la Ley No 19.880, o contenciosoadministrativas, acción de nulidad y recurso de protección, cuando ello sea pertinente" 21 .

Por último, resulta discutible que la resolución de calificación ambiental sea siempre el único acto de término de la evaluación ambiental si observamos disposiciones como los artículos 24 y 25 de la Ley $N^{\circ} 19.300$, en los que se parte de la base que los proyectos respectivos cuentan con una resolución de calificación ambiental favorable para que sus titulares puedan obtener autorizaciones y Permisos Ambientales Sectoriales de organismos sectoriales.

b) En relación ahora con la proposición $2^{\mathrm{a}}$ ), no puede darse por descontado que todo acto anterior a la resolución de calificación ambiental en un procedimiento de evaluación de impacto ambiental sea un acto administrativo intermedio.

Resulta a lo menos discutible que los actos que Moraga denomina "equivalentes del acto terminal ${ }^{22 “}$, dictados en este caso en el marco de un proceso de evaluación de impacto ambiental y que no constituyen una resolución de calificación ambiental propiamente tal, no tengan el carácter de actos de término ${ }^{23}$.

En este sentido, los pronunciamientos de los órganos del Estado con competencia ambiental que participan del procedimiento de evaluación ambiental, y dan forma, primero, a los informes consolidados de solicitud de aclaraciones, rectificaciones o ampliaciones; y luego, al informe consolidado de evaluación; deben reunir prácticamente las mismas exigencias que fija el artículo 41 de la Ley No 19.880 para los actos de término, lo que nos lleva a afirmar, desde la perspectiva de tales organismos, que la naturaleza jurídica de sus actos (anteriores a la Resolución de Calificación Ambiental) admite interpretaciones.

c) Para abordar la proposición $3^{a}$, a su turno, y afirmar que se trata de una proposición que no debe ser asumida como un absoluto, conviene hacer mención de un hecho objetivo que podría invocarse como argumento

petente de conformidad con lo dispuesto en los artículos 17, No 8 y 18 , No 7 de la Ley No 20.600 .

${ }^{21}$ BermúdeZ, Jorge, Fundamentos del Derecho ambiental (Valparaíso, Ediciones Universitarias de Valparaíso, 2007), p. 216.

${ }^{22}$ Moraga, Claudio, La actividad formal de la Administración del Estado, en PANTojA, Rolando (coordinador), Tratado de Derecho administrativo (Santiago, Abeledo Perrot, 2010), VII, p. 106.

${ }^{23} \mathrm{~V}$. gr., los actos dictados en virtud de lo dispuesto en los artículos 14 ter (control de admisibilidad), 15 bis (término anticipado de evaluación de un estudio de impacto ambiental) y 18 bis de la Ley No 19.300 (término anticipado de evaluación de declaración de impacto ambiental). 
de autoridad ${ }^{24}$ : la Corte Suprema ha estimado en ocasiones que los actos trámite $^{25}$ sí poseen aptitud suficiente para afectar el ejercicio de derechos:

En noviembre de 2010, la Sala Constitucional de la Corte Suprema confirmó la sentencia con que se acogió un recurso de protección fundado en un pronunciamiento sectorial dictado en el marco de un proceso de evaluación de impacto ambiental ${ }^{26}$. Después, en mayo de 2012, la misma sala de la Corte entendió que un acto anterior a la resolución de calificación ambiental como es un Informe Consolidado de Evaluación, puede ser ilegal y apto para afectar los derechos reconocidos en el artículo 19 No 1 y 8 CPol. ${ }^{27}$. Por último, en junio de 2012, la Tercera Sala de la Corte Suprema revocó una sentencia de primera instancia y acogió un recurso de protección fundado en la ilegalidad de la resolución que declaraba admisible una declaración de impacto ambiental como instrumento de evaluación para un proyecto ${ }^{28}$.

\section{ANÁLISIS LÓGICO Y JURÍDICO}

Si llevamos el criterio jurisprudencial que se comenta al plano de la lógica formal, debemos primero visualizar los argumentos que lo integran y una vez que contamos con ellos y sus proposiciones, trasladarlos a la estructura de los silogismos ${ }^{29}$.

${ }^{24}$ Para un estudio de los argumentos de autoridad, véase el capítulo IV de WESTON, Anthony, Las claves de la argumentación ( $10^{\mathrm{a}}$ edición actualizada, traducción castellana de Jorge F. Malem Seña, Barcelona, Ariel, 2007), p. 55 ss.

${ }^{25} \mathrm{~A}$ la hora de buscar explicaciones para la poca atención que reciben y han recibido históricamente los actos trámite -no obstante que puedan afectar per se el ejercicio de derechos y la validez del acto terminal-, compartimos la apreciación que hace CORDERO, Luis, El procedimiento administrativo: desarrollo y perspectivas, en PANTOJA, Rolando (coordinador), Derecho administrativo. 120 años de cátedra (Santiago, Editorial Jurídica de Chile, 2008), p. 327, citando a Ponce Solé: “Así, la influencia de la figura del acto administrativo terminal, como institución central de la formación histórica del Derecho Administrativo, ha provocado que el procedimiento administrativo sea mirado a través de sus lentes (perspectiva estática). El enfoque tradicional basado en la impugnación del acto definitivo o resolución ha provocado que el procedimiento sea considerado como un elemento formal de éste y, al ser mera forma, de escasa trascendencia”.

${ }^{26}$ Recurso rol No $7167-2010$, sentencia redactada por el magistrado señor Pedro Pierry.

${ }^{27}$ Recurso rol No 2463-2012, sentencia redactada por el magistrado señor Sergio Muñoz.

${ }^{28}$ Recurso rol No 3141-2012, sentencia redactada por el ministro señor Sergio Muñoz.

${ }^{29}$ La Real Academia Española, Diccionario de la Lengua Española (22a edición, Ma- 
$1^{\circ}$ Premisa mayor:

$$
\text { Primer silogismo. }
$$

Los actos del procedimiento de evaluación de impacto ambiental, previos a la resolución de calificación ambiental, son actos intermedios;

$2^{\circ}$ Premisa menor:

El acto supuestamente ilegal en que se funda el Recurso de Protección integra el procedimiento de evaluación, pero es anterior a la resolución de calificación ambiental;

$3^{\circ}$ Conclusión:

El acto administrativo en que se funda la acción es de mero trámite.

$1^{\circ}$ Premisa mayor:

$$
\text { Segundo silogismo }
$$

Los actos intermedios no son aptos para lesionar el ejercicio de derechos constitucionales como los del artículo $19 \mathrm{~N}^{\circ} 2$ y 8

$2^{\circ}$ Premisa menor:

El recurso de protección que se conoce se funda en un acto intermedio supuestamente ilegal.

\section{$3^{\circ}$ Conclusión:}

El acto administrativo en que se funda la acción es de carácter intermedio, en razón de lo cual no puede afectar el ejercicio de los derechos del artículo 19 No 2 y 8 y el recurso debe ser rechazado.

Si revisamos estos argumentos a la luz de las reglas de los silogismos, concluimos que se trata de silogismos categóricos ${ }^{30}$, válidos desde un punto de vista lógico formal, pero con problemas de justificación externa en el plano de la justificación jurídica, ya que al controlar la solidez de los argumentos constatamos una fundamentación insuficiente en relación con las premisas mayores.

Siguiendo el esquema de análisis que propone Moreso, es posible verificar que se está ante premisas poco sólidas y, por lo tanto, ante argumentos de validez dudosa ${ }^{31}$. Todo lo cual afecta la calidad de los razonamientos, y en definitiva se traduce en una menor justificación y racionalidad de las

drid, Espasa, 2001), II, p. 2.066, define “silogismo" como: "argumento que consta de tres proposiciones, la última de las cuales se deduce necesariamente de las otras dos".

${ }^{30}$ Hamamé, Eva, Modos de razonamiento (Santiago, Universidad Diego Portales, 2000), pp. 28 ss.

${ }^{31}$ Moreso, José Juan, Lógica, argumentación e interpretación en el Derecho (Barcelona, UOC, 2006), pp. 122-123. 
decisiones jurisdiccionales, viéndose así debilitada la fuerza persuasiva de las respectivas sentencias ${ }^{32}{ }^{33}$.

Como afirma el magistrado Carlos Cerda, "el juicio jurisdiccional es el objeto propio del verbo rector 'juzgar'. En tanto que el razonamiento judicial es el prototipo del verbo rector 'conocer'. Como lo que hacemos los jueces es conocer para juzgar, tenemos que el juicio está inserto en nuestro razonamiento" ${ }^{34}$.

De este modo, una sentencia que exhibe falta de motivación ${ }^{35}$ contendrá un razonamiento con debilidades, y en consecuencia, lo que se decida en ella contará con menor aceptabilidad entre sus destinatarios, afectándose la legitimidad del discurso jurisdiccional ${ }^{36}{ }^{37}$.

\section{RECURSO DE PROTECCIÓN Y SANA CRÍTICA}

Como es bien sabido, el recurso de protección es una acción de emergencia que se incorporó al ordenamiento jurídico chileno con el Acta Constitucional No 3 del año $1976^{38}$, y con aquella se pretende cautelar el ejercicio de ciertos

${ }^{32}$ Coincidimos aquí con Pozo, Nelson, Razonamiento judicial (Santiago, Puntolex, 2009), p. 253, cuando afirma: "siempre que haya que argumentar significa que hay que decidir y toda decisión a que se arribe debe estar provista de razones, de forma tal que podría perfectamente decirse que la argumentación es la compañía de la decisión, en la medida que argumentar y decidir son facetas de un mismo proceso".

${ }^{33}$ Pozo, Nelson, La sentencia: el juez y la sentencia (Santiago, Ediciones Jurídicas La Ley, 1993), p. 294, afirma que "La relación entre parte considerativa y parte resolutiva de la sentencia, es en el plano de los juicios una relación de un juicio inferido a partir de un razonamiento anterior, en otras palabras una conclusión de juicios previos".

${ }^{34}$ CERDA, Carlos, El Juicio jurisdiccional y sus limitaciones normativas a la luz de los artículos 19 a 24 del Código Civil, en CERDA, Carlos (editor), Razonamiento judicial. Cuaderno de Análisis Jurídico (Santiago, Universidad Diego Portales y Centro de Desarrollo Jurídico Judicial de la Corporación de Promoción Universitaria, 1995), V, p. 768.

${ }^{35}$ Entendemos con Melo, Ma Soledad - Pozo, Nelson, Las leyes del pensamiento en el Derecho (Santiago, Ril, 2013), p. 283, que\}: "falta de motivación significa ausencia de motivos que sustenten el dispositivo de la sentencia, o que dichos argumentos son inatingentes o insuficientes para sustentar la decisión".

${ }^{36}$ CERda, Carlos, Iuris dictio (Santiago, Editorial Jurídica de Chile, 1992), p. 206.

${ }^{37}$ En relación con este punto, una mitad del Tribunal Constitucional sostuvo en 2012: "Que si la decisión judicial sólo puede recaer sobre una solución legitima; para ser aceptable desde un punto de vista jurídico y atribuirle validez, es evidente que la motivación de la sentencia es esencial. Ella es la justificación -no la explicación- de la resolución; se trata de un discurso cerrado, de clausura: una vez dictado el fallo, debe contener todos los requisitos de la justificación, no pudiendo ser variado o modificado". Considerando $9^{\circ} \mathrm{de}$ la sentencia No 203411, redactada por el ministro señor Hernán Vodanovic Schnake.

${ }^{38}$ So to KLOss. Eduardo, Derecho administrativo. Temas fundamentales (Santiago, LegalPublishing Chile, 2010), p. 629. 
derechos que la misma Constitución reconoce, frente a omisiones y actos arbitrarios o ilegales.

El régimen jurídico de la acción lo compone hoy el artículo $20 \mathrm{CPol} \cdot{ }^{39}$ y el Auto acordado sobre tramitación y fallo del recurso de protección de las garantías constitucionales vigente, dictado por la Corte Suprema el año 1992. Régimen jurídico que en ningún momento distingue entre tipos de actos administrativos recurribles -en relación con el derecho a un medio ambiente libre de contaminación, la igualdad ante la ley, ni ninguno de los demás derechos tutelados-, franqueando una garantía en términos genéricos para quien sienta amagado los derechos del artículo 20 producto de un acto u omisión ilegal, ya sea que provenga de privados, o de órganos públicos.

De otro lado, en el artículo $5^{\circ}$ inciso $2^{\circ}$ del Auto Acordado se lee: " $L a$ Corte apreciará de acuerdo con las reglas de la sana crítica los antecedentes que se acompañen al recurso y los demás que se agreguen durante su tramitación".

Constatamos entonces que el conjunto de normas que regula el recurso de protección no contiene distinciones entre tipos de actos recurribles, y de otro lado, que los magistrados se encuentran en el imperativo de apreciar los antecedentes probatorios de los recursos con arreglo a un sistema de valoración determinado: el de la sana crítica. Sistema que según afirma Couture remite a criterios de lógica y de experiencia "por acto valorativo del juez" y que en opinión de Cárdenas, contiene "la obligación de fundamentar las sentencia, rasgo que distingue a este sistema de la libre convicción" ${ }^{\text {‘1 }}$.

Por lo tanto, una decisión recaída en un recurso que carezca de fundamentación importará un distanciamiento de la Corte que la dicta con las normas que la Corte Suprema dictó para tramitar y fallar las acciones de protección, restando de paso efectividad a la tutela judicial.

\section{VI. “ACtos trámite” para otros órganos del Estado}

Al regular el principio de imparcialidad en la Ley $N^{\circ} 19.880$, el legislador fijó requisitos específicos para los actos administrativos "que afectaren los

${ }^{39}$ En el caso del recurso de protección ambiental, su regulación constitucional desde el año 2005 es la que sigue: "Procederá, también, el recurso de protección en el caso del $N^{\circ} 8$ del artículo 19, cuando el derecho a vivir en un medio ambiente libre de contaminación sea afectado por un acto u omisión ilegal imputable a una autoridad o persona determinada" (artículo 20, inciso $2^{\circ}$ ).

${ }^{40}$ Couture, Eduardo Juan, Obras. Estudios de Derecho procesal civil, III: Pruebas en materia civil (Buenos Aires, Puntolex, 2010), III,2, p. 169.

${ }^{41}$ CÁRdenAs, Marjorie, La motivación de las sentencias como un elemento de la sana critica y el recurso de casación en el fondo, en Revista de Derecho del Consejo de Defensa del Estado, 24 (2010), p. 89. 
derechos de losparticulares", sin entrar a distinguir la naturaleza de tales actos ni su lugar en el procedimiento administrativo, atendiendo exclusivamente a sus efectos ${ }^{42}$.

En el mismo cuerpo de normas del año 2003, el legislador estableció en forma expresa que los actos trámite pueden determinar la imposibilidad de continuar un procedimiento y producir la indefensión de los administrados, permitiendo por ello su impugnación al interior de los procedimientos administrativos ${ }^{43}$ en que se encuentren insertos ${ }^{44}$.

Por su parte, la Contraloría General de la República ha interpretado las normas de los recursos administrativos generales sosteniendo que si el legislador no ha hecho distingos, tampoco corresponde hacerlos a un órgano como el Servicio de Evaluación Ambiental, independiente de la modalidad que adopte el acto a la luz del artículo 3 de la Ley No 19.880. Dictaminando así la eventual procedencia de los recursos de reposición, jerárquico y extraordinario de revisión, incluso, contra un acto constitutivo de una "declaración de juicio" ${ }^{45}$.

\section{CONCLUSIONES}

Los tribunales superiores de justicia no han seguido una línea clara a la hora de resolver recursos de protección fundados en la supuesta ilegalidad de actos del procedimiento de evaluación de impacto ambiental.

De la lectura de las sentencias de los "recursos de protección ambiental" comprendidas en el período que cubre el trabajo se infiere un cierto consenso entre los magistrados en cuanto a la naturaleza terminal de la resolución de calificación ambiental, y por lo tanto, respecto de la eventual procedencia de recursos contra ella. Con todo, cuando los recursos se fundan en un acto anterior del procedimiento de evaluación, puede darse por cumplido el

${ }^{42}$ Artículo 11 inciso $2^{\circ}$ de la Ley No 19.880.

${ }^{43}$ Artículo 15 inciso $2^{\circ}$ de la Ley $\mathrm{N}^{\circ} 19.880$.

${ }^{44}$ La Sala Constitucional de la Corte Suprema fijó como uno de los criterios para declarar la nulidad de un Decreto municipal modificatorio de un plan regulador comunal: "la omisión y defectuosa emisión de actos trámites que produjeron la indefensión de los administrados" (Recurso de casación rol No 2054-2013. Considerando $10^{\circ}$ de la sntencia redactada por el abogado integrante señor Jorge Baraona.

${ }^{45}$ Dictamen No 7.620-2013. El contralor concluye que los actos por medio de los cuales el Servicio de Evaluación Ambiental responde consultas de pertinencia son declaraciones de juicio de la entidad pública, por tanto, actos administrativos, y que al carecer tal procedimiento de consulta y respuesta de reglas especiales, debe regirse por las normas supletorias de la Ley $\mathrm{N}^{\circ} 19.880$, quedando así los actos que le den forma sujetos a los recursos que franquea esta última. 
presupuesto de la acción como puede estimarse que el acto no es apto para afectar el ejercicio de derechos, rechazándose la acción.

La situación descrita se observa no solo en los fallos de las Cortes de Apelaciones que conocen de recursos en primera instancia, sino también en fallos dictados por la Corte Suprema en su calidad de tribunal de apelación. Constatándose que una misma sala del máximo tribunal puede presentar interpretaciones en sentidos diversos con muy poca distancia en el tiempo.

Luego, y específicamente cuando las Cortes conocen de recursos de protección ambiental y se sirven del distingo entre actos "trámite" y "decisorios" frente a actos del procedimiento de evaluación, constatamos que en las sentencias se expresa, a lo sumo, que los actos trámite no tendrían la aptitud suficiente para afectar el ejercicio de derechos como los del $19 \mathrm{~N}^{\circ}$ 2 o el $19 \mathrm{~N}^{\circ} 8$, sin embargo, el argumento no es desarrollado, quedando a nivel de enunciado.

Dicha falta de desarrollo argumental importa desentenderse del principio de juridicidad y de la sana crítica como sistema de valoración, permitiendo a los magistrados descartar antecedentes probatorios sin hacerse cargo de la valoración de los mismos. Lo anterior redunda en una menor efectividad de la tutela judicial y en una reducción de las posibilidades de la parte recurrente de ejercer un control sobre la decisión, disminuyéndose en definitiva el campo de acción del mecanismo de protección frente a derechos tales como el de igualdad ante la ley o a vivir en un medio ambiente sano.

Es evidente la necesidad de un mayor desarrollo argumental del criterio que en ocasiones aplican los ministros y de una mayor consistencia jurisprudencial. Máxime si tenemos en cuenta que se trata de un criterio exclusivamente judicial, sin base normativa, y que otros órganos del Estado hacen, mutatis mutandis, una interpretación distinta de los actos administrativos, admitiendo que ellos, sean de trámite o finales, pueden tener aptitud suficiente para producir agravio y ser impugnados.

\section{BiBLIOGRAFÍA}

Silva Cimma, Enrique, Derecho administrativo chileno y comparado. Actos, contratos y bienes (Santiago, Editorial Jurídica de Chile, 1995), V.

Rojas, Jaime, Notas sobre el procedimiento administrativo establecido en la Ley $N^{\circ} 19.880$, en Revista de Derecho del Consejo de Defensa del Estado, 11 (2004).

VARGAS, RAFAEL, Instituciones de Derecho ambiental. El recurso de protección ambiental (Santiago, Metropolitana, 2007).

Caldera, Hugo, Tratado de Derecho administrativo (Santiago, Ediciones Parlamento, 2001), II.

BERMÚDEZ, Jorge, Fundamentos del Derecho ambiental (Valparaíso, Ediciones Universitarias de Valparaíso, 2007). 
Moraga, Claudio, La actividad formal de la Administración del Estado, en PANToja, Rolando (coordinador), Tratado de Derecho administrativo (Santiago, Abeledo Perrot, 2010), VII.

WeSTON, Anthony, Las claves de la argumentación (10ª edición actualizada, traducción castellana de Jorge F. Malem Seña, Barcelona, Ariel, 2007).

CORDERo, Luis, El procedimiento administrativo: desarrollo y perspectivas, en PANTOJA, Rolando (coordinador), Derecho administrativo. 120 años de cátedra (Santiago, Editorial Jurídica de Chile, 2008).

Real Academia Española, Diccionario de la Lengua Española (22a edición, Madrid, Espasa, 2001), II.

Hamamé, Eva, Modos de razonamiento (Santiago, Universidad Diego Portales, 2000).

Moreso, José Juan, Lógica, argumentación e interpretación en el Derecho (Barcelona, UOC, 2006).

Pozo, Nelson, Razonamiento judicial (Santiago, Puntolex, 2009).

Pozo, Nelson, La sentencia: el juez y la sentencia (Santiago, Ediciones Jurídicas La Ley, 1993).

CERDA, Carlos, El Juicio jurisdiccional y sus limitaciones normativas a la luz de los artículos 19 a 24 del Código Civil, en Cerda, Carlos (editor), Razonamiento judicial. Cuaderno de Análisis Jurídico (Santiago, Universidad Diego Portales y Centro de Desarrollo Jurídico Judicial de la Corporación de Promoción Universitaria, 1995), V.

Melo, Ma Soledad - Pozo, Nelson, Las leyes del pensamiento en el Derecho (Santiago, Ril, 2013).

CERDA, Carlos, Iuris dictio (Santiago, Editorial Jurídica de Chile, 1992).

Sото KLoss. Eduardo, Derecho administrativo. Temas fundamentales (Santiago, Legal PublishingChile, 2010).

Couture, Eduardo Juan, Obras. Estudios de Derecho procesal civil, III: Pruebas en materia civil (Buenos Aires, Puntolex, 2010), III,2.

CÁRDEnAs, Marjorie, La motivación de las sentencias como un elemento de la sana critica y el recurso de casación en el fondo, en Revista de Derecho del Consejo de Defensa del Estado, 24 (2010). 